\title{
Well-Defined Processes and Their Effects on Business Process Outsourcing Vendor's Success: an Integrated Framework
}

\author{
Zhanhe Du ${ }^{1,2}$ Xiuwu Liao ${ }^{1}$ \\ ${ }^{1}$ School of Management, Xi'an Jiao Tong University, Xi'an, 710049, China \\ ${ }^{2}$ School of Economics and Administration, Xi' an University of Technology, Xi'an, \\ 710054, China \\ Email:duzh008@hotmail.com,liaoxiuwu@mail.xjtu.edu.cn
}

\begin{abstract}
Offshore business process outsourcing (BPO) has been prevalent for two decades, but there are many failures. Although some literature analyzes the reason of failures from process viewpoint, there is still not a clear understanding about what are well-defined processes and their effects on BPO vendor's success are still undisclosed. In this paper, we give a definition of well-defined processes and some criteria to measure them, which fills the gap of absence of a clear definition of well-defined processes. In addition, we propose an integrated framework from production cost economics (PCE), relational exchange theory (RET) and transaction cost economies (TCE) perspectives, through which we talk about how well-defined processes affect BPO vendor's success. Well-defined processes affect BPO vendor's success through facilitating internal productivity, strengthening external relationship and improving contract enforcement.
\end{abstract}

Keywords: Business process outsourcing, Well-defined processes, Internal productivity, Relationship, Contract enforcement

\section{Introduction}

With the globalization and increased development of information technology, interest in the global business process outsourcing (BPO) industry has grown considerably. Notwithstanding any substantial potential savings, a number of firms are unable to realize the benefits of global business process outsourcing. For example: during 2005-2008, 60\% of organizations outsourcing customer facing services would face customer defections and incur hidden costs that may nullify savings(Alster, 2005) ; Aron and Singh (2005) indicated that half the firms that outsourced processes offshore failed to generate expected financial benefits. These failures perhaps result from that clients were ill prepared for the outsourcing initiative and lacked a well-developed strategy and understanding of how outsourcing would work (Willcocks et al., 1996) and that the BPO firm's performance may not be aligned with the expectations of the client. Is it enough for explaining the failures? Recently, some literature has stressed the importance of managing the interdependencies of the processes, suggesting that the inability of the service 
providers and their clients to manage the interdependencies of the processes is an important reason for the BPO failure (Aron and Singh, 2005; Mani et al., 2007). Moreover, Narayanan et al. (2010) highlight that the effective process integration, both within the service provider and with their client, may alleviate poor performance. Wüllenweber et al. (2008) argues the impact of process standardization on BPO success, resulting from better monitoring opportunities and facilitated communication and coordination. Although recent literature has stressed the significant of process management, there is a gap that is absence of a clear understanding and a rigorous definition about what are rigorous, well-defined processes under global BPO contextual environment, which is mentioned in existing literature limitation. In order to close this gap, we conduct this work that discusses what are rigorous, well-defined processes and their effects on BPO success from vendor's perspective.

Developing a well-defined and adhered-to process is a global BPO best practice (Trent \& Monczka, 2002). Global BPO project execution is an interdependent, dynamics exercise that requires both client and vendor to work together via a formalized process of collaboration. With stable processes, performance is easily measured. Krishnan et al. (2000) stated that disciplined methods and practices which are measured using the Capability Maturity Model (CMM) are expected to result in better control over the software development process.

GUPTA (2010) argues that without well-defined processes one cannot trust process changes or count on the desired outcomes. Trent and Monczka (2005) assert that the presence of a well-defined process was found to be the strongest differentiator between successful and less successful global efforts. Well-defined processes accelerate learning as participants become familiar and experienced with a defined process. It "builds in" best practices and knowledge that enhance the likelihood of success. Perhaps most importantly, it allows organizations to document measure and continuously improve. A well-defined global outsourcing process also helps overcome many of the differences that exist among locations - such as social culture and laws, personnel skills and business culture - thus aligning participants and practices around the world (Takeuchi \& Nonaka, 1986; Trent \& Monczka ,2005).

Although the importance of process standardization or process integration has been highlighted in many areas which includes global outsourcing, unfortunately a clear definition of well-defined processes is absent, thus which will put researchers and practitioners in vagueness or ambiguousness. To close this gap we try to give a clear definition of well-defined processes and then we analyze how well-defined processes affect BPO vendor success.

In order to discover the effect path of well-defined processes to global BPO success, we would conduct our research from production cost economics (PCE) perspective, relational exchange theory (RET) perspective and transaction cost economies (TCE) perspectives (illustrated in figure 1). This is consistent with Narayanan et al. (2010) and Wüllenweber et al. (2008), which argue that high quality management of process will facilitate the coordination across multi-department within vendor firm, also facilitate external coordination between clients and vendors due to task uncertainty and complexity.

\section{Theoretical background}




\section{Production cost economies (PCE)}

PCE is the part of production economics addressing the production cost side. Production costs include any direct and indirect costs for producing a service or product as well as the delivery and service costs. From a PCE perspective, firms treat outsourcing as a decision that compares production costs of internal operations with the price offered on the market (Wüllenweber et al., 2008). Economies of scale arise from the ability to perform activities more efficiently at larger volumes; economies of skill arise from accumulated knowledge learning from larger volumes transactions (Porter 1985). Narayanan et al. (2010) argue the high performance of vendor resulting from internal integration which facilitate coordination across department boundaries within vendor firm. Wüllenweber et al. (2008) argues that there is a direct impact of process standardization on BPO success, due to production cost economies.

\section{Relational exchange theory (RET)}

RET has been used as the most appropriate theory to explain inter-organizational behavior. It is based on the notion that the exchanging parties are in mutual agreement about expecting better outcomes from their collaboration than from other forms of exchange (Goles \& Chin, 2002). In the outsourcing literature, RET has been used to analyze different factors to explain relationship aspects. Goles and Chin (2005) present a detailed and systematic conceptualization of relational factors including attributes (commitment, consensus, cultural compatibility, trust, interdependence) and processes (communication, conflict resolution, coordination, cooperation, integration) of an outsourcing relationship. The most fundamental process in this context is considered to be communication. It enables other dimensions of relationship quality such as conflict resolution, coordination, cooperation, or consensus (Wüllenweber et al., 2008).

\section{Transaction cost economies (TCE)}

Modern theories of the firm argue that environmental uncertainty or complexity lead to imperfect or incomplete contracts (Milgrom and Roberts 1992). Complete contracts are considered infeasible or at least associated with extensively high transaction costs (Williamson 1975). Drawing on TCE, some outsourcing studies have examined the effect of the degree of contract completeness on outsourcing success. For example, Aubert et al. (2003) find that, among others, less measurability in the outsourced activities leads to less complete contracts and, as a consequence, to less successful outsourcing. Poppo and Zenger (2002) show that managers are less satisfied with outsourced IT services when they could not easily measure its performance. Wüllenweber et al. (2008) suggest a mediated effect resulting from contractual governance advantages due to higher transparency and better monitoring possibilities.

\section{Research model and hypotheses}

The theoretical underpinnings for each of the hypothesized relationships, is provided in the following sections. Fig. 1 illustrates the hypothesized influence of well-defined processes on BPO vendor's success. Our model thus emphasized the effects of well-defined processes on BPO vendor's success from three perspectives-PCE, RET, and TCE perspectives. Drawing on previous work on process integration, inter-organizational relationships, and offshore business process outsourcing, our model was developed; the internal productivity, relationship, and contract 
enforcement are three antecedents of BPO vendor's success, the well-defined processes impact on internal productivity, relationship, and contract enforcement. It demonstrates how the well-defined processes affect BPO vendor's success.

\subsection{Well-defined processes}

The global sourcing processes share certain features: a widely communicated and understood process that becomes the foundation for pursuing integrated global sourcing; the designation of a process owner who has responsibility for reviewing and improving the process; and "lessons learned" sessions conducted at the end of each project, with results forwarded to global team members and leaders. In addition, contracts are continuously monitored, reviewed and reestablished as required (Trent \& Monczka, 2002).

Process standardization includes common definitions of metrics, common languages that maintain the integrity of business rules, process logic and data, and flexibility (Ramakumar and Cooper 2004). GUPTA (2010) gives two critical aspects of the process in well-defined process: Clearly defined performance targets and a comprehensive list of process inputs to achieve the target performance.

Integrating the existing literature, we give an integrated understanding of well-defined processes from three aspects: rigorous and well-defined internal processes, rigorous and well-defined external processes, processes measurement management. Well-defined processes are characterized by clearly documented and updated internal and external processes, rigorous industry standards (CMM, CMMI, Six Sigma, etc.), regular phase gate reviews, "lessons learned" sessions, lessons and experiences sharing, clear and standardized report process, good communication, process to quickly respond to production problems and to RFPs, clearly defined business requirements and project goals, a set of clearly defined performance metrics and relationship metrics, standardized SLAs, and project cost and schedule metrics. We suggest the detailed items measuring well-defined processes shown in appendix A.

\subsection{BPO vendor's success}

In most literature from client perspective, outsourcing success was generally analyzed from strategic, technological, and economic perspectives. Lee and Kim added the user's perception of outsourcing performance, such as reliability, relevancy, timeliness, accuracy, currency, and completeness of information (Han et al., 2008). Relative to literature from client perspective some literature from vendor perspective analyzed BPO success from perception of project quality, management of cost and labor input to the project (Mao et al., 2008); other literature from profit level, market share, and cost reduction (Narayanan et al., 2010 ). Based on previous work we analyze the vendor's success from strategic, technological, and economic perspectives which is consistent with client perspective but different measurement since vendors operating their performance by different way. Specifically, strategic evaluation includes client satisfaction, knowledge captive, reputation, relationship duration, and improvement of competitive advantage; technological evaluation includes improvement of tech capability, service delivery quality, and personnel training; economic evaluation includes cost reduction, profit level. 


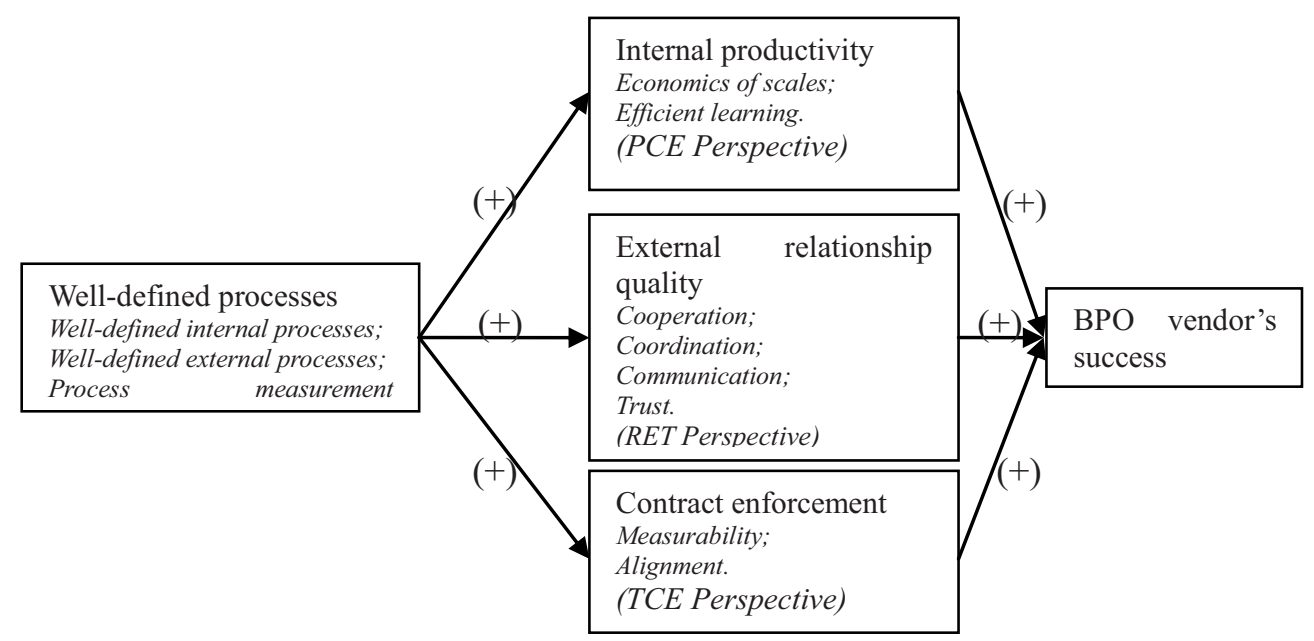

Fig. 1: Research conceptual model.

\subsection{Hypotheses development}

\subsubsection{Relationship between well-defined processes and internal productivity}

As mentioned in much BPO literature, BPO task is very complex. Narayanan et al. (2010) define task complexity as the degree of customization and knowledge intensity of the tasks the firm undertakes. Task complexity concerns the extent to which the BPO task is sophisticated and difficult to standardize, requiring a great deal of specialized knowledge to undertake the task. Many of the BPO functions require embedded, complex multi-knowledge (Willcocks et al., 2004; Youngdah and Ramaswamy, 2008). The execution excellence of these BPO services may often depend on the coordination between each process and sub-process shipped offshore in a vendor firm internally (Aron and Singh, 2005).

Due to the complexity of BPO task, BPO operation needs coordination across multiple departments. As well-defined processes provide documents of internal processes, industry standards and well-defined interfaces, vendors can effectively coordinate between various subtasks and various departments. As a result, this will facilitate internal process integration as well as process standardization. Narayanan et al. (2010) argue that internal process integration can help in seamless coordination across multi-tasks within the operations of the service provider. Krishnan et al. (2000) argue that the methods and practices adopted by software development professionals to develop and maintain software are believed to have significant impact on the project outcomes in terms of development cost and product quality. Wüllenweber et al. (2008) argues that process standardization enable vendors to achieve economies of scale (reducing average costs per unit) since a vendor needs to bundle similar business processes from different clients, also enable vendors to achieve economies of skill since process standards can encompass experiences or 'good practice' from other firms and projects, which can be positively related to process performance and thus BPO success, this is consistent with production cost economies.

Improving operational performance 
and reducing costs by decreasing process errors, facilitating communication, or just profiting from expert knowledge will positively impact on BPO vendor's success. Thus we propose hypotheses as follows:

H1a: Well-defined processes positively affect a vendor's internal productivity due to PCE perspective.

$H 1 b$ : Internal productivity is positively associated with BPO vendor's success.

\subsubsection{Relationship between well-defined processes and external relationship quality}

Exchange partners are facing changing business and technology environments during a BPO venture. RET argues that the exchanging parties are in mutual agreement about expecting better outcomes from their collaboration than from other forms of exchange (Goles and Chin 2002). Increased task complexity may not just increase coordination within the firm, but may also increase the requirement of coordination with the client. Further, processes also need to be responsive to client needs and to the uncertainties stemming from any changes (Narayanan et al., 2010). According to our definition about well-defined processes, well-defined processes can guarantee well-defined standard reporting procedures, information security, assignment of a dedicated project manager, fully understanding of mutual objective and expectations, a process to quickly respond to problems, a set of clearly defined relationship metrics, and new personnel training. If well-defined processes are available in BPO vendor firm, the process can be more easily understood by both parties and, thus, facilitate communication about process execution, changes, and improvements. Well-defined processes therefore give the BPO venture a common ground for mutual understanding and facilitates information sharing (Wüllenweber et al. 2008), which result to mutual trust, commitment and mutual interdependence, thus leading to a high quality relationship between vendors and clients (Lee, 2001; Han et al.,2008).

Lee (2001) argues that a cooperative relationship based on trust, business understanding, benefit and risk sharing, conflict, and commitment is critical to maximize the strategic, economic, and technological benefits for outsourcing. Other literature also highlights the importance of relationship quality to BPO success, asserting that high quality relationship contributes to clients' satisfaction, mood cheerful, long-term strategic alliance et al (Lee and Kim 1999; Kern\& Willcocks, 2002; Goles and Chin 2005). These all have strong impact on BPO vendor's success. According to above analysis, we propose hypotheses as follows:

H2a: Well-defined processes positively affect external relationship quality with clients due to RET perspective.

$H 2 b$ : External relationship quality is positively associated with BPO vendor's success.

\subsubsection{Relationship between well-defined processes and contract enforcement}

Kern and Willcocks (2002) expose the nature of BPO contract which is characterized by uncertainty and the measurement difficulty. The uncertainty and the measurement difficulty of BPO contract pose two challenges for the design and execution of contracts in BPO. First, it is difficult to define the stream of services and appropriate performance metrics ex ante. Complexity and volume uncertainty will make contract clauses more difficult to write, simply because these activities will be more complex to describe and more difficult to predict. Second, the potential for rent seeking 
deters the development of long-term collaborative relationships that can realize the value from outsourcing (Wüllenweber et al., 2008). These above challenges will let contract more incomplete which is associated with extensively high transaction costs (Williamson 1975).

According to our definition about well-defined processes, well-defined processes present a process to quickly respond to RFPs, a set of clearly defined performance metrics, appropriate project cost and schedule metrics, standardized SLA's, systems to measure adherence to the level of service contract terms.

Drawing on TCE perspective, these will facilitate alignment of contractual governance and higher measurability, which effectively lower incompleteness and uncertainty of contract (Wüllenweber et al., 2008). Measurability of the transactions strongly increases the probability of outsourcing decisions. Highly predictable or easy to measure activities will make complete contracting easier. Similarly, increased measurability will mean that more measures and better ones will be included in the contract, in a way that makes the supplier performance will be more observable and verifiable (Aubert et al., 2003). Therefore, both measurability and lack of uncertainty will lead to more complete contracts, thus facilitating the enforcement of contract.

As contractual governance is critical to BPO success, excellent contractual enforcement will positively affect BPO vendor's success. According to above analysis, we propose hypotheses as follows:

H3a: Well-defined processes positively affect contractual enforcement due to TCE perspective.

H3b: Contractual enforcement is positively associated with BPO vendor's success.

\section{Conclusions}

This work has two contributions. First, this article gives a clear understanding about what are well-defined processes in the context of BPO. We provide some items to measure what are well-defined processes, which can help the BPO vendors identify the extent to which the work processes are well established, also help researchers who direct attention on BPO especially from processes viewpoint. Second, this article provides an integrated framework which discloses how well-defined processes affect BPO vendor's success from PCE, RET, and TCE perspectives. From PCE perspective we argue that the vendors will only be able to achieve an efficient cost basis by generating economies of scale if it can operate well-defined processes and as well as provide one standardized process to all clients. The vendors will be able to achieve an efficient learning basis by generating economies of skill since process standards can encompass experiences or 'good practice' from other firms and projects. From RET perspective we argue that operating well-defined processes allows a better understanding about how the business operates and can be improved. This facilitates communication and coordination between clients and vendors and allows realigning disparate goals and actions to solve day-to-day problems, which leads to a higher level of mutual trust. Thus better mutual understanding, efficient communication and cooperation, and high level of trust will facilitate relationship between vendors and their clients. From TCE perspective we argue that well-defined processes imply better process documentation and transparency which lead to higher measurability of process output and to an easier implementation of performance control points, thus, facilitating alignment of contractual governance and higher measurability, which effectively lower 
incompleteness and uncertainty of contract. Above all, this integrated framework can be used to guide the further empirical research.

As far as limitation of this work concerned, future research especially more detailed factors and effects in each perspective need to be further researched; empirical study is pursued to identify the framework.

\section{Appendix A. Suggested well-defined processes measurement}

(1) Rigorous and well-defined internal processes

Existence and documentation of internal processes

1. Our global outsourcing internal processes are clearly

documented

2. The documentation of our internal global outsourcing processes are up-to-date

3. Our global outsourcing internal processes are easy to follow

4. Our global outsourcing internal process design follows industry standards (CMM, CMMI, Six Sigma, etc.)

5. We have high level of CMM certification

6. We have process in place to ensure information security (e.g. ISO027001)

\section{Utilization of existing processes}

7. We actually use our documented internal processes for global outsourcing projects

8. We require project members to utilized the defined processes

9. There is a systems to help project members to track and adhere to defined processes

10. Our global outsourcing internal processes are fully communicated to project members
11. We are able to consistently follow the defined internal processes for different outsourcing projects

\section{Internal Process Practices}

12. We have regular phase gate reviews of the status of global outsourcing projects

13. We assign process champions to each of the processes that are to be completed

14. We conduct "lessons learned" sessions at the end of each project

15. Lessons and experiences from earlier projects are documented and shared with future projects

(2) Rigorous and well-defined external processes

Existence of client process and standards

16. We and our outsourcing clients all highly value the rigorous and well-defined processes

17. Clear and standardized report process between us and our outsourcing clients is available

18. Report process between us and our outsourcing clients is easy to understand and follow

19. We and our outsourcing clients are consistent and mutual understanding on project object

20. Our outsourcing client's processes are clearly documented

21. The documentation of the client outsourcing process is up-to-date

22. The documentation of the client outsourcing process is easy to understand and follow

Client relationships and practices

23. We have good communication with our outsourcing clients 
24. Our outsourcing client always assigns a dedicated project coordinator

25. We fully understand our outsourcing client's objective and expectations

26. Our outsourcing client have a process to quickly respond to production problems

27. Our outsourcing client have a process to quickly respond to RFPs

28. Our outsourcing clients provide new personnel training for us on the established processes

(3) Measurement Management

29. Client's business requirements and project goals are clearly defined.

30. A set of clearly defined performance metrics were used to measure project success.

31. A set of clearly defined relationship metrics were used to manage the relationship between the client and vendor

32. Appropriate project cost and schedule metrics were consistently used

33. Standardized SLAs exist to adequately measure performance against requirements

34. Global outsourcing contracts are continuously managed, reviewed, and reestablished as required

\section{References}

[1] Alster, N. (2005). Customer disservice. CFO 21 (13), 40-44.

[2] Aron, R., Singh, J.V. (2005).Getting offshoring right. Harvard Business Review(December), 135-143.

[3] Aron, R., Singh, J.V., 2005.Getting offshoring right. Harvard Business Review (December), 135-143.

[4] Aubert, B. A., Houde, J.F., Patry, M., \& Rivard, S.
(2003).Characteristics of IT outsourcing contracts. In 36th Hawaii International Conference on System Sciences, Hawaii, 2003.

[5] Davenport, T. H. (2005) The coming commoditization of processes. Harvard business review(June), 1-8

[6] Goles, T., \& Chin, W.W. (2002). Relational exchange theory and IS outsourcing: Developing a scale to measure relationship factors.In R. Hirschheim, A. Heinzl, \& J. Dibbern (Eds.), Information systems outsourcing (pp. 221-250). Berlin: Springer.

[7] Goles, T., \& Chin, W.W. (2005). Information systems outsourcing relationship factors: Detailed conceptualization and initial evidence. The DATA BASE for Advances in Information Systems, 36(4), 47-67.

[8] GUPTA, P. (2010). A Foundation for Improvement and Excellence. QUALITY (June), p18

[9] Han, H.S., Lee, J.N., Seo, Y.W. (2008). Analyzing the impact of a firm's capability on outsourcing success: a process perspective. Information and Management 45, 31-42.

[10] Kern, T., Willcocks, L. (2002). Contract, Control and 'Presentation' in IT Outsourcing: Research in Thirteen UK Organizations. In F. Tan, Advanced Topics in Global Information Management, Volume 1 (pp. 227-249), Hershey, PA: Idea Group Publishing.

[11] Kern, T., Willcocks, L. (2002). Exploring relationships in information technology outsourcing: The interaction approach. European Journal of Information Systems, 11,3-19.

[12] Kern, T., Willcocks, L. P. (2002). Exploring relationships in information technology outsourcing: The interaction approach. European 
Journal of Information Systems, 11, 3-19.

[13] Krishnan, M. S., Kriebel, C. H., Kekre, S., Mukhopadhyay, T. (2000). An Empirical Analysis of Productivity and Quality in Software Products. Management Science, Vol. 46, No. 6, pp. 745-759

[14] Lee J. N. (2001) The impact of knowledge sharing, organizational capability and partnership quality on IS outsourcing success. Information \& Management 38, 323-335

[15] Lee, J. N., Kim, Y. G. (1999). Effect of partnership quality on IS outsourcing success: Conceptual framework and empirical validation. Journal of Management Information Systems, 15(4), 29-61.

[16] Mani, D., Barua, A., Whinston, A. (2007). A model of contingent governance choice and performance in business process outsourcing: the effects of relational and process uncertainty. In: International DSI Conference and APDSI Conference,Bangkok, Thailand, July

[17] Mao J. Y., Lee J. N., Deng C. P. (2008).Vendors' perspectives on trust and control in offshore information systems outsourcing Information \& Management 45, 482-492

[18] Milgrom, P., Roberts, J. (1992). Economics, organization and management. Englewood Cliffs: Prentice-Hall.

[19] Narayanan, S., Jayaraman, V., Luo, Y., Swaminathan, J. M., .(2010). The antecedents of process integration in business process outsourcing and its effect on firm performance. Journal of Operations Management, In Press, Corrected Proof, Available online 24 May 2010

[20] Poppo, L., Zenger, T. (2002). Do formal contracts and relational governance function as substitutes or complements? Strategic Management
Journal, 23(8), 707-725.

[21] Porter, M. E. (1985). Competitive advantage. New York: Free Press.

[22] Ramakumar, A., Cooper, B. (2004). Process standardization proves profitable. Quality, 43(2), 42-45.

[23] Takeuchi, H., Nonaka,I. (1986) The New New Product Development Game Harvard Business Review 64,137-146

[24] Trent, R. J., Monczka, R. M. (2002). Pursuing competitive advantage through integrated global sourcing. Academy of Management Executive 16 , no. $2: 66-80$.

[25] Trent, R. J., Monczka, R. M. (2005). Achieving Excellence In Global Sourcing. MIT Sloan Management Review Fall 47 (1) pp.24-32

[26] Willcocks, L. P., Hindle, J., Feeny, D. F., Lacity, M. C. (2004). IT and business process outsourcing: The knowledge potential. Information Systems Management, 21,7-15

[27] Willcocks, L. P., Lacity, M. C., \& Kern, T. (1999). Risk mitigation in IT outsourcing strategy revisited: Longitudinal case research at LISA. Journal of Strategic Information Systems, 8(3), 285-314.

[28] Williamson, O. E. (1975). Markets and hierarchies: analysis and antitrust implications. A study in the economics of internal organization. London: Free Press.

[29] Wüllenweber, K., Beimborn, D., Weitzel, T., König, W. (2008). The impact of process standardization on business process outsourcing success. Information Systems Frontier 10:211-224

[30] Youngdahl, W., Ramaswamy, K., 2008. Offshoring knowledge and service work: a conceptual model and research agenda. Journal of Operations Management 26(2), 212-221. 